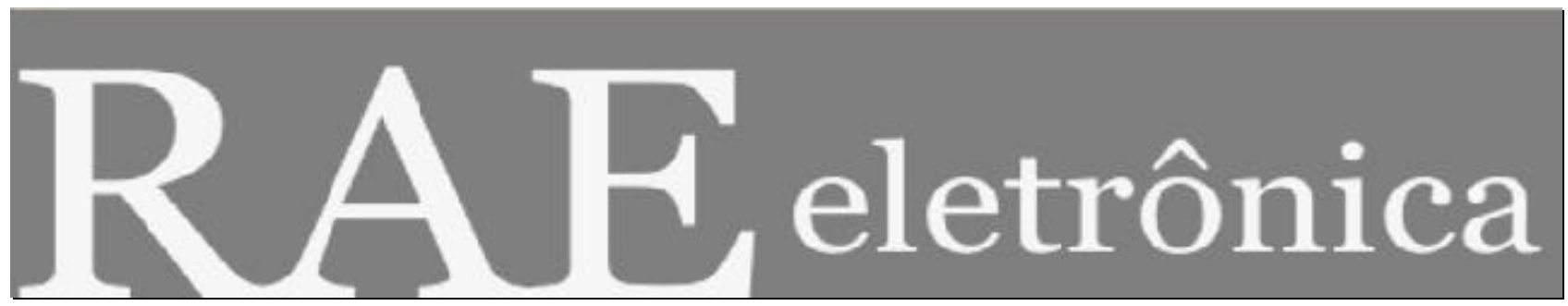

\title{
ORGANIZAÇÕES DE APRENDIZAGEM OU APRENDIZAGEM ORGANIZACIONAL
}

Por:

\section{Yeda Swirski de Souza}

RAE-eletrônica, v. 3, n. 1, Art. 5, jan./jun. 2004

http://www.rae.com.br/eletronica/index.cfm?FuseAction=Artigo\&ID=1812\&Secao=ORGANIZA\&Vol ume $=3 \&$ Numero $=1 \&$ Ano $=2004$

CCopyright, 2004, RAE-eletrônica. Todos os direitos, inclusive de tradução, são reservados. É permitido citar parte de artigos sem autorização prévia desde que seja identificada a fonte. A reprodução total de artigos é proibida. Os artigos só devem ser usados para uso pessoal e nãocomercial. Em caso de dúvidas, consulte a redação: redacao@ rae.com.br.

A RAE-eletrônica é a revista on-line da FGV-EAESP, totalmente aberta e criada com o objetivo de agilizar a veiculação de trabalhos inéditos. Lançada em janeiro de 2002, com perfil acadêmico, é dedicada a professores, pesquisadores e estudantes. Para mais informações consulte o site www.rae.com.br/eletronica.

RAE-eletrônica

ISSN 1676-5648

(C2004 Editora: Fundação Getulio Vargas - Escola de Administração de Empresas de São Paulo
F U N D A G Ã O GETUUO VARGAS

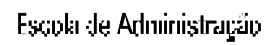
de Eripipresàs de Săo Paulo 


\title{
ORGANIZAÇÕES DE APRENDIZAGEM OU APRENDIZAGEM ORGANIZACIONAL
}

\section{RESUMO}

Este artigo tem como objetivo chamar à atenção para possib ilidades de desenvolvimento e otimização de processos de aprendizagem organizacional, levando-se em conta as realidades sociais e culturais dos contextos organizacionais. Destaca-se que existem caminhos para a prática da aprendizagem organizacional que não se restringem às idéias de $A$ quinta disciplina de Peter Senge e sua proposição das organizações de aprendizagem, que é abordada aqui em uma perspectiva crítica. Para o desenvolvimento e otimização de processos de aprendizagem é proposta a noção de oportunidades de aprendizagem organizacional, inspirada nos estudos sobre aprendizagem organizacional e na pesquisaação que tem sido desenvolvida nesse campo específico. São apresentadas duas situações organizacionais que se revelaram como oportunidades de aprendizagem organizacional em dois contextos organizacionais diferentes: (i) reuniões de trabalho, no contexto de uma unidade de uma empresa de telefonia; (ii) feiras setoriais, no contexto de um cluster coureiro-calçadista.

\begin{abstract}
The aim of this article is to propose an action approach to organizational learning. The role of cultural and social context in organizational learning is discussed. It is supported a critical view toward Peter Senge's proposition at The Fifth Discipline as a way to inspire effective organizational learning actions. The notion of organizational learning opportunities is proposed as an alternative way to reach organizational learning actions. This notion is based on different features of organizational learning processes and on action-research developed at this field. Examples of organizational learning opportunities at specific social and cultural contexts are presented: work meetings and trade fairs.
\end{abstract}

\section{PALAVRAS-CHAVE}

Aprendizagem organizacional, organizações de aprendizagem, cultura organizacional, mudança organizacional, pesquisa-ação.

\section{KEY-WORDS}

Organizational learning, learning organizations, organizational culture, organizational change, actionresearch. 


\section{Introdução}

O conceito de aprendizagem organizacional ganhou notoriedade na década de noventa, embora presente há mais tempo na literatura sobre teoria econômica da firma e teoria das organizações. A ênfase nesse conceito e sua retomada são atribuídas ao forte valor explicativo que apresenta para processos de mudança organizacional, lembrando-se que a preocupação em favorecer aprendizagens emerge em um contexto competitivo no qual a inovação em produtos e processos é nuclear à sobrevivência de organizações. Se em suas abordagens iniciais, no contexto da teoria econômica da firma, falar em aprendizagem organizacional significa avaliar resultados de desempenho, na medida em que o conceito é apropriado pela teoria das organizações, o foco passa a ser os processos. Trata-se, assim, de buscar responder, por meio do conceito, como organizações agem para conquistar os resultados que indicam a realização de aprendizagens. Busca-se compreender que estruturas organizacionais, que políticas de gestão de pessoas, que cultura, que valores, que tipos de liderança, que competências, que aspectos, enfim, podem favorecer ou obstaculizar processos de aprendizagem.

Com alto valor explicativo e analítico, paradoxalmente, o conceito de aprendizagem organizacional, não se reverte facilmente em prescrições para a ação, deixando em aberto, na literatura acadêmica, a questão de como, afinal, promover aprendizagem organizacional.

Nesse ensejo, surge a proposição das learning organizations (organizações de aprendizagem) que se difunde através do livro A quinta disciplina, de Peter Senge ${ }^{i}$. Embora, o autor jamais afirme que se trata de um modelo a ser seguido, copiado ou imitado, o corpo de idéias contido no texto de A quinta disciplina é apreciado pelo seu valor prescritivo e, assim, bastante diferente da literatura acadêmica. Apesar de atraente e, pode-se dizer, amplamente disseminado, muitas interrogações têm sido levantadas com relação às efetivas possibilidades de aplicação do ideário contido em $A$ quinta disciplina. Mais do que isso, uma análise mais detida da proposição das organizações de aprendizagem as circunscreve à dimensão específica da fantasia.

Assim, a questão de como promover aprendizagem continua pedindo respostas e é nesse desafio que alinhamos aqui algumas proposições que se deduzem dos estudos que caracterizam e analisam processos de aprendizagem nas organizações e de intervenções conduzidas com a estratégia da pesquisa-ação.

Em uma primeira parte deste artigo, apresentamos uma análise de A quinta disciplina enquanto discurso produzido no campo social. O intuito é compreender como esse texto engaja o leitor; que aspectos estão implícitos aos enunciados; como o texto dissemina-se e ganha expressão no mercado editorial. A análise desses aspectos contribui para o estabelecimento de leitura crítica de A quinta disciplina.

Em uma segunda parte, desenvolvemos a noção de oportunidades de aprendizagem organizacional. Entendemos que a noção de oportunidades de aprendizagem organizacional permite estabelecer estratégias de intervenção voltadas a favorecer processos de aprendizagem. Em uma terceira parte, apresentamos duas situações organizacionais que se revelaram como oportunidades de aprendizagem organizacional em dois contextos organizacionais diferentes: (i) reuniões de trabalho, no contexto de uma unidade de uma empresa de telefonia; (ii) feiras setoriais, no contexto de um cluster coureirocalçadista.

\section{Organizações de Aprendizagem: a terra encantada?}

$\mathrm{O}$ interesse explosivo pelo conceito de aprendizagem organizacional entre empresas, acadêmicos, 
consultores, publicações especializadas, tem acompanhado o exemplo de outras noções que surgem como a última solução do momento, ou a idéia capaz de colocar uma empresa à frente de seus concorrentes. Assim como já ocorreu com a gestão da qualidade, há o risco de o modismo da aprendizagem organizacional resultar em que idéias importantes sejam banalizadas e ganhem absoluto descrédito (HAWKINS, 1994).

Hawkins (1994) considera que A quinta disciplina é um texto que traz consigo o risco desse tipo de banalização e aponta para dois aspectos capazes de confundir o leitor.

A referência a Arquimedes, no primeiro capítulo de $A$ quinta disciplina, ajuda a compreender o primeiro desses aspectos. "Dê-me uma alavanca e moverei o mundo ii ", sugere que nos situamos em uma posição exterior ao mundo e, neste caso, às organizações que pretendemos mudar. Se a proposição das organizações de aprendizagem é oferecida como a alavanca de Arquimedes, resta saber quem é o sujeito aí. Quem é sujeito capaz de estar na condição de exterioridade e, portanto, apto a mover organizações que padecem de falta de pensamento sistêmico e das diferentes "doenças" que decorrem dos modos que o mundo ocidental, sua cultura, crenças e valores, consagraram para aprender e organizar? (HAWKINS, 1994).

Para Hawkins (1994), o texto de Peter Senge, embora ofereça caminhos instigantes para perceber organizações e seus problemas em uma perspectiva sistêmica e pós-cartesiana, ainda guarda uma abordagem mecanicista, já que A quinta disciplina resulta em um instrumento a ser manejado, ou como é sugerido, um conjunto de disciplinas a ser praticado. Além disso, resta a dúvida sobre como garantir ao usuário dessas disciplinas uma condição diferenciada com relação aos problemas que o texto denuncia. Ou seja, já que a falta de pensamento sistêmico é uma herança da civilização ocidental, como assegurar que uma prática inspirada em A quinta disciplina não se dê sob o signo dessa mesma herança, ou seja, como assegurar que sua prática não seja também burocratizada?

Outro risco, apontado por Hawkins (1994), está em confundir meios e fins, objetivos e instrumentos. $A$ quinta disciplina é um texto que oferece uma proposição e um convite para a ação e, assim, mais do que um conjunto de idéias é um conjunto de exercícios. O leitor, ou melhor, o praticante de A quinta disciplina deve supor ou aceitar que a ferramenta é boa em si mesma. Ou seja, é preciso de antemão aceitar que ao praticar A quinta disciplina, os problemas de uma organização encontrarão soluções. Em outras palavras, o texto se oferece como uma panacéia e, como tal, sedutora, mas inconveniente, se buscamos promover aprendizagens que sejam cruciais para organizações em seus contextos e culturas específicos.

Um estudo baseado na análise do discurso do trabalho de Peter Senge torna ainda mais aguda a compreensão das razões que fazem suas proposições tão facilmente assimiláveis ao discurso do cotidiano das empresas (JACKSON, 2000).

Para Jackson (2000), a proposição das organizações de aprendizagem pode ser considerada como uma visão retórica, isto é, um conjunto de narrativas que envolvem um grande grupo em uma realidade simbólica.

Uma visão retórica é construída a partir de algumas fantasias que operam como meios para o estabelecimento de uma interpretação. Essas fantasias manifestam se na forma de uma palavra, frase ou proposição que interpreta eventos do passado, prevê eventos futuros ou negligencia eventos atuais que são removidos no tempo e no espaço das atividades de um grupo. As fantasias que sustentam uma visão retórica preenchem necessidades psicológicas. 
Não apenas as organizações de aprendizagem mas também outros conceitos em administração que se tornaram modismos (excelência, reengenharia, gestão da qualidade) são considerados pelo autor como visões retóricas. Soma-se, ainda, na sustentação de uma visão retórica a sanção de um agente externo. No caso dos modismos da administração, um guru pode agir como a autoridade que garante a legitimidade e credibilidade da visão retórica.

Quatro temas-fantasia básicos são identificados por Jackson (2000, pp. 211-16) na proposição das organizações de aprendizagem, a saber:

1. Vivendo em um mundo insustentável: o tema aparece nos textos de Peter Senge quando a infelicidade organizacional é situada em um contexto social mais amplo, sendo as organizações consideradas como microcosmos da sociedade. Assim, os esforços de mudança organizacional são também dirigidos às disfunções de uma cultura maior. Ao falar sobre a crise social e ecológica da sociedade ocidental, Peter Senge produz o sentido de urgência, o pano de fundo expressivo para justificar a ação de mudança;

2. Ganhando controle, mas não controlando: Peter Senge argumenta sobre a importância da autoridade e poder estarem situados em nível local, ou seja, argumenta em favor de que cada trabalhador, cada indivíduo, possa ter a liberdade de desenvolver suas idéias e experimentar os efeitos de sua ação. Ao mesmo tempo, argumenta que o exercício das cinco disciplinas é capaz de manter a organização sob controle. A promessa implícita neste tema consiste na superação dos problemas das relações de trabalho, com uma proposição que parece transcender aos costumeiros dilemas que acompanham a repartição de autoridade e poder no contexto das organizações;

3. O novo trabalho do líder: Os papéis de designer, professor e facilitador, adquirem um novo sentido nas organizações de aprendizagem e demandam do líder novas competências. Aos executivos de topo são recomendadas três tarefas básicas: construir uma base de propósitos e valores fundamentais para a organização; desenvolver políticas, estratégias e estruturas capazes de expressar as idéias orientadoras em direções para o negócio; e criar processos de aprendizagem efetivos através dos quais políticas, estratégias e estruturas possam ser continuamente aprimoradas. Há também nas proposições de Peter Senge, indicações para o papel das lideranças intermediárias. Assim, recomendando e descrevendo papéis, o trabalho de Peter Senge sugere conter orientações para os indivíduos em diferentes níveis e funções da organização, que são, em geral, acompanhadas por histórias de experiências bem sucedidas;

4. Tornando possível a partir de micromundos: Micromundo é um termo que descreve um ambiente virtual criado com a tecnologia da informação e que simula uma situação do mundo real. Um micromundo pode ajudar administradores e suas equipes a aprender sobre seus problemas, experimentando em um ambiente virtual as consequiências de suas decisões. Através desse recurso, gerentes ganham a oportunidade de transpor as condições imediatas de tempo e espaço para situações mais confortáveis, em que os problemas não só organizacionais, mas da sociedade e do ambiente podem ser adequadamente conduzidos. O potencial da tecnologia da informação na criação de ambientes virtuais cada vez mais complexos e interativos sugere, por um lado, que as experiências de aprendizagem podem parecer cada vez mais verossímeis. Por outro lado, a visão retórica é reforçada, já que no manejo de realidades virtuais, o mundo insustentável que justifica a proposição das organizações de aprendizagem, ganha soluções.

A visão retórica das organizações de aprendizagem é ainda sustentada por uma rede internacional 
estabelecida entre academia, empresas, consultores com origem no Massachusetts Institute of Technology (MIT) e, hoje, designada pela marca Society for Organizational Learning (SoL). Um trabalho continuado em publicações, eventos, palestras, além do espaço na web, ocupam-se da mídia e difusão desse ideário.

No Brasil, a nona ${ }^{\text {iii }}$ edição de A quinta disciplina em português e a tradução quase que imediata de outros livros da série sugerem o interesse que a proposição das organizações de aprendizagem desperta no leitor brasileiro.

A observação informal junto a profissionais que se dedicam à gestão de recursos humanos no contexto brasileiro, sugere que a proposição de A quinta disciplina é bem acolhida enquanto esperança de uma administração mais equânime e capaz de criar organizações e sociedade mais justas e melhores. Entendemos que, na condição de indivíduos, grupos, organizações e sociedade que buscam seu lugar e identidade entre as mudanças que vêm a reboque dos processos de globalização, o discurso de A quinta disciplina pode soar como o canto das sereias, como uma aposta sedutora. Contudo, a cultura que se encontra nas organizações, os modelos mentais e valores das lideranças, os problemas cotidianos dos gerentes e, com efeito, suas visões e escopo de ação limitados tendem mais a afastar do que aproximar os interessados em A quinta disciplina das tentativas de implementar suas proposições. Diante do grande desencontro entre a proposição das organizações de aprendizagem e o cotidiano das empresas, às vezes, não resta ao praticante muito mais do que a paralisia no que se refere a intervenções voltadas à aprendizagem.

Encontrar caminhos para intervir, desenvolver, promover aprendizagem organizacional e transpor os estudos analíticos e compreensivos para proposições gerenciais permanece ainda como um desafio. Nessa direção, alguns trabalhos na linha da pesquisa-ação têm sido desenvolvidos, os quais, a nosso ver, merecem atenção, já que podem inspirar proposições voltadas ao desenvolvimento e otimização da aprendizagem organizacional. $\mathrm{Na}$ seção que segue apresentamos uma proposição voltada ao desenvolvimento da aprendizagem nas organizações, calcada em características dos processos de aprendizagem e inspirada na pesquisa-ação descrita na literatura.

\section{Oportunidades de aprendizagem organizacional: uma proposição}

A noção de oportunidades de aprendizagem organizacional parte de duas interrogações básicas: (i) que aprendizagens são cruciais para uma organização, (ii) como essas aprendizagens podem ser desenvolvidas e otimizadas considerando-se as realidades sociais e culturais específicas dos contextos organizacionais?

Essas interrogações trazem já alguns pressupostos provenientes dos estudos sobre aprendizagem organizacional. Os seguintes aspectos são destacados:

a) Que a aprendizagem organizacional é chave para a competitividade e sobrevivência de organizações;

b) Que a aprendizagem organizacional é um fenômeno ao mesmo tempo individual e coletivo;

c) Que a aprendizagem organizacional está intrinsecamente relacionada à cultura das organizações;

d) Que a aprendizagem organizacional é um fenômeno que apresenta uma dinâmica paradoxal, já que aprender e organizar são fenômenos antitéticos. 
O primeiro aspecto acima identificado é a associação entre competitividade e aprendizagem organizacional que está bem expressa na revisão de literatura apresentada por Dodgson (1993). A aprendizagem organizacional é vista como a busca de manter e desenvolver competitividade, produtividade e inovação em condições tecnológicas e de mercado incertas. O autor esclarece que, embora o conceito esteja historicamente associado às análises econômicas do desenvolvimento de novas indústrias, tecnologias e programas de Pesquisa \& Desenvolvimento, é retomado com ênfase na análise dos processos de transformação em organizações na esteira das mudanças no cenário econômico internacional, a partir dos anos oitenta.

O segundo aspecto, acima identificado, é o caráter ao mesmo tempo individual e coletivo da aprendizagem organizacional. A aprendizagem individual não é sinônimo de aprendizagem organizacional, contudo não haverá aprendizagem organizacional sem a aprendizagem individual. Esse aspecto já está presente em Simon (1969) que define aprendizagem organizacional como o crescimento de insights e reestruturações bem sucedidas de problemas organizacionais por indivíduos que têm impacto nos elementos estruturais e nos resultados da organização.

Organizações, diferentemente de indivíduos, desenvolvem e mantêm sistemas de aprendizagem que, não apenas influenciam seus membros imediatos, mas são também transmitidos para outros, via histórias e normas organizacionais. Assim, seria um erro concluir que a aprendizagem organizacional não é nada mais do que o resultado cumulativo da aprendizagem dos membros, pois as organizações têm sistemas cognitivos e memórias, ou seja, desenvolvem visões de mundo e ideologias, mapas mentais, normas e valores que se preservam para além da presença de membros individuais. Por outro lado, há muitos casos em que as organizações sabem menos que seus membros (HERDBERG, 1981; ARGYRIS \& SCHÖN,1978).

Por um lado, não são os conhecimentos privados de cada indivíduo que estão em jogo na aprendizagem organizacional mas, sim, aqueles conhecimentos que são de algum modo compartilhados e que mobilizam a ação). Por outro lado, como afirma Argyris (1992), são indivíduos, agindo como agentes da organização, que produzem ações aptas à aprendizagem ou, ao contrário, que podem inibir ou produzir barreiras à aprendizagem. Para Argyris a aprendizagem do tipo aprender-a-aprender, isto é, aquela que propõe a revisão dos pressupostos orientadores da ação, encontra uma expressão singular no indivíduo. Identificar a teoria-em-uso na ação individual tem o sentido de buscar as variáveis que governam a ação. Esse é o primeiro passo necessário a qualquer proposição de aprendizagem e, como efeito, de mudança (ARGYRIS, 1992a, 1992b).

Kim (1993) propõe um modelo integrado de aprendizagem organizacional composto pelo modelo experiencial da aprendizagem e a noção de modelos mentais. A noção de modelos mentais, produz uma síntese entre as crenças individuais e as crenças compartilhadas. Os modelos mentais representam os resultados das aprendizagens realizadas pelos indivíduos. As aprendizagens individuais contribuem de modo recíproco para as aprendizagens dos pequenos grupos e da organização como um todo, produzindo-se modelos mentais compartilhados.

Os modelos mentais guardam regras intangíveis que orientam a ação. Ou seja, transcendem à memória organizacional contida em rotinas escritas. Não são meramente o repositório de informações, mas processos ativos de construção de teorias da realidade que têm efeitos na ação.

Kim dirá ainda que os modelos mentais inserem-se numa weltanschauung da organização, que é, afinal de contas, uma expressão da cultura organizacional, de pressupostos fortemente enraizados. 
Ao destacarmos este aspecto da aprendizagem organizacional na produção da noção de oportunidades de aprendizagem organizacional, estamos valorizando, por um lado, as decisões e ações de indivíduos que tem impacto nas ações e desempenho da organização e, por outro lado, a noção de que ações e decisões derivam de modelos mentais. Com isso, deve-se salientar que, embora possa estar no domínio de ações e decisões individuais, a aprendizagem organizacional, associada a modelos mentais, situa-se em um campo pouco tangível. Modelos mentais são expressão de crenças, valores, senso comum e, assim, estão fortemente associados à cultura das organizações.

O terceiro aspecto, acima identificado, na composição da noção de oportunidades de aprendizagem organizacional é a associação entre cultura e aprendizagem organizacional. Essa associação já se entretece nas relações entre aprendizagem individual e aprendizagem organizacional. A aprendizagem individual no contexto organizacional não pode ser reduzida a um ato isolado promovido pelo indivíduo. As organizações têm suas histórias de sucesso e fracasso, mitos, heróis, símbolos, regras tácitas e explícitas de aceitação e exclusão, etc., ou seja, uma cultura (ou culturas) que as caracteriza e as distingue de outras organizações (Schein, 1990, 1996). Além disso, é preciso considerar que boa parte do conhecimento compartilhado em uma organização é tácito, fato que confere especial valor à transmissão de saber e aprendizagem sócioculturais ( NONAKA, 1994 ).

O estudo de Cook e Yanow (1993) sobre os processos de aprendizagem entre alguns dos melhores produtores de flautas do mundo é bastante esclarecedor e inspirador para compreender as relações entre aprendizagem e cultura organizacional. Como afirmam os autores “(...) O conhecimento necessário para produzir as flautas da melhor qualidade, assim como jogar basquete ou executar uma sinfonia, não reside em um indivíduo, mas na organização como um todo. A organização não nasceu com tal conhecimento, precisou aprendê-lo iv (p.443)".

Cook e Yanow (1993) propõem como conceito para aprendizagem organizacional “(...) acquiring, sustaining, or changing of intersubjective meanings through the artifactual vehicles of their expression and transmission and the collective actions of the group (p.449)".

Os autores acrescentam que esses sentidos, sejam eles adquiridos por novos membros ou criados pelos membros existentes, surgem e são mantidos nas interações entre os membros na organização. Essas interações podem adquirir diferentes modalidades. Trata-se não só da interação face a face, mas também da interação mediada pelos artefa tos da cultura da organização como os objetos simbólicos e a linguagem.

São, sobretudo, as relações entre cultura e aprendizagem organizacional que indicam, a nosso ver, a necessidade de se identificar no contexto de cada organização oportunidades de aprendizagem. Ou seja, buscar os momentos e as situações que, já inscritos na cultura e nas formas privilegiadas de ação, sejam propícios à aprendizagem.

Finalmente, o quarto aspecto destacado na composição da noção de oportunidades de aprendizagem organizacional é seu caráter antitético. Como propõem Weick e Westley (1996), a expressão aprendizagem organizacional é um oxímoro. Ou seja, aprender e organizar são dois processos paradoxalmente diferentes. Enquanto organizar sugere a ordem, aprender sugere desordem sendo que é a composição entre ordem e desordem o que está na raiz dos processos de mudança e aprendizagem organizacional. Nessa perspectiva, Weick e Westley propõem que a aprendizagem organizacional é facilitada quando a ordem está justaposta à desordem, pois, nesses momentos, as pessoas conseguem perceber o que é, rotineiramente, imperceptível. Os autores acrescentam que os momentos de aprendizagem não são óbvios e não podem ser confundidos com as atividades formalmente voltadas à 
aprendizagem. Momentos de aprendizagem ocorrem em diferentes contextos. Tomando-se Piaget como inspiração, pode-se dizer que aprendizagens podem ocorrer quando um elemento novo desordena uma adaptação anterior, produzindo um novo equilíbrio em um novo patamar de conhecimento. Tratando-se de aprendizagens coletivas, é preciso considerar que a aprendizagem se dará com a interação e construção de sentidos coletivos. Nessa perspectiva, os sentidos individuais se desacomodam através da interação, do diálogo, da alteridade intrínseca à dinâmica das relações nos contextos organizacionais.

Retomando as interrogações propostas no início desta seção - (i) que aprendizagens são cruciais para uma organização?; (ii) como essas aprendizagens podem ser desenvolvidas e otimizadas, considerandose as realidades sociais e culturais específicas do contexto organizacional? - e observando-se as características dos processos de aprendizagem organizacional acima descritos, contamos com uma proposição preliminar que pretende contribuir para o planejamento e intervenção para o desenvolvimento e otimização de processos de aprendizagem. O quadro abaixo apresenta um sumário dessa proposição.

\begin{tabular}{|l|l|l|}
\hline Características de Processos de Aprendizagem & $\begin{array}{l}\text { Questões orientadoras para o desenvolvimento de } \\
\text { processos de aprendizagem }\end{array}$ \\
\hline $\begin{array}{l}\text { A aprendizagem organizacional é chave para } \\
\text { a competitividade e sobrevivência de } \\
\text { organizações. }\end{array}$ & $\begin{array}{l}\text { Que aprendizagens e que conhecimentos são cruciais } \\
\text { para assegurar competitividade à organização? }\end{array}$ \\
\hline $\begin{array}{l}\text { A aprendizagem organizacional é um } \\
\text { fenômeno ao mesmo tempo individual e } \\
\text { coletivo. }\end{array}$ & $\begin{array}{l}\text { Quem são os atores-chave na busca de informação? } \\
\text { Quais e como são as estratégias e políticas da } \\
\text { organização para o desenvolvimento de competências } \\
\text { associadas à aprendizagem entre os atores-chave? } \\
\text { Que condiçôes estruturais e de interação os atores- } \\
\text { chave encontram para disseminar informações? }\end{array}$ \\
\hline $\begin{array}{l}\text { Aprendizagem organizacional está } \\
\text { intrinsecamente relacionada à cultura das } \\
\text { organizações; }\end{array}$ & $\begin{array}{l}\text { Quais são as formas de interação privilegiadas na } \\
\text { cultura da organização? } \\
\text { Como pessoas e equipes tem aprendido ao longo da } \\
\text { história da organização? } \\
\text { Quais são as áreas ou equipes da organização mais } \\
\text { permeáveis a novas aprendizagens? }\end{array}$ \\
\hline $\begin{array}{l}\text { Aprendizagem organizacional é um fenômeno } \\
\text { que associa ordem e desordem. }\end{array}$ & $\begin{array}{l}\text { Que situações específicas, inscritas na cultura da } \\
\text { organização e não necessariamente associadas à } \\
\text { educação formal, apresentam potencial de } \\
\text { aprendizagem? } \\
\text { Como o sentido coletivo é construído? }\end{array}$ \\
\hline
\end{tabular}

F IGURA I - QUADRO DAS OPORTUNIDADES DE APRENDIZAGEM ORGANIZACIONAL Fonte: elaborada pela autora do artigo 


\section{REUNIÕES DE TRABALHO E FEIRAS SETORIAIS COMO OPORTUNIDADES DE APRENDIZAGEM}

\section{Reuniões de trabalho}

As reuniões são atividade habitual nas organizações e, assim, prática inscrita nas rotinas e na cultura de organizações. Constituem-se também em espaço reservado para a interação e conversação. Essas duas características das reuniões de trabalho levam a interrogar sobre seus efeitos para a aprendizagem organizacional.

Os comentários que seguem referem-se à uma reunião de trabalho semanal e regular de equipe responsável por uma unidade de serviços de uma empresa de telefonia investigada por meio da observação-participante. No período em que se realizou o estudo (novembro de 1997 - junho de 1998), mudanças importantes ocorreram na empresa. A exemplo da maior parte das empresas estatais brasileiras, essa Companhia vivia um processo de privatização. Numa primeira etapa, $49 \%$ das ações passam ao capital privado e, numa segunda etapa, mais 39\% das ações são privatizadas, restando, assim, ao Estado apenas 12\% das ações. Duas empresas assumem a maior parte dessas ações, sendo que uma delas é uma empresa da Espanha e a outra é uma holding que atua no setor das comunicações na região. O processo de privatização responde a uma política governamental voltada à desestatização da economia. No setor da telefonia, esse processo é acompanhado por contratos de gestão entre governo e empresa, que estabelecem metas de desempenho e penalidades para o não cumprimento das mesmas.

Os participantes da reunião são gerentes ou coordenadores responsáveis por diferentes atividades da unidade de serviços. Suas responsabilidades são tipicamente de gerências intermediárias, ou seja, o acompanhamento das estratégias propostas pelo topo da organização e sua condução aos níveis operacionais. As atividades consistem em todas aquelas próprias ao trabalho de telefonia como: o atendimento a clientes nas lojas de serviços; o atendimento de reparos; a engenharia de instalação e manutenção de planta externa; a instalação e manutenção de equipamentos; o desenvolvimento de telefonia pública; o desenvolvimento de telefonia residencial; vendas; finanças; administração geral e recursos humanos,

Os objetivos explícitos e formalmente estabelecidos para essa reunião são informar sobre o andamento dos processos de trabalho, analisar problemas e buscar soluções. Entretanto, a reunião traz também a oportunidade para uma variedade de interações. Há conversas informais entre os participantes sobre temas relacionados ou não com o trabalho ou a empresa. O humor é freqüente, bem como os comentários sobre aspectos da vida pessoal. As mudanças na empresa, a assimilação do novo sistema de gestão, as novas rotinas de trabalho, as novas pressões, as demissões, a relação com os gestores espanhóis são temas que aparecem freqüentemente. As conversações contribuem para que os participantes troquem idéias sobre as mudanças em andamento e, assim, construam e compartilhem sentidos que ajudam a compreender o que acontece na Companhia e a orientar suas ações. Pode-se dizer que interagindo esses gerentes constroem conhecimentos tácitos e explícitos. Esses conhecimentos passam a integrar as suas ações.

O problema aqui é se podemos considerar essas reuniões de trabalho como oportunidades de aprendizagem organizacional. Acompanhando as questões orientadoras para o desenvolvimento de processos de aprendizagem acima propostas, pode-se estabelecer a seguinte avaliação: 


\begin{tabular}{|c|c|}
\hline \begin{tabular}{|llrr} 
Questões orientadoras & para & o \\
desenvolvimento & de & processos & de \\
aprendizagem & & & \\
\end{tabular} & $\begin{array}{l}\text { Avaliação de reuniões de trabalho como oportunidades } \\
\text { de aprendizagem em uma unidade de serviço de } \\
\text { empresa de telefonia }\end{array}$ \\
\hline $\begin{array}{l}\text { Que aprendizagens e que conhecimentos são } \\
\text { cruciais para assegurar competitividade à } \\
\text { organização? } \\
\text { Quem são os atores-chave na busca de } \\
\text { informação? } \\
\text { Quais e como são as estratégias e políticas da } \\
\text { organização para o desenvolvimento de } \\
\text { competências associadas à aprendizagem } \\
\text { entre os atores-chave? } \\
\text { Que condições estruturais e de interação os } \\
\text { atores-chave encontram para disseminar } \\
\text { informações? }\end{array}$ & $\begin{array}{l}\text { As reuniões favorecem à aprendizagens } \\
\text { estrategicamente relevantes como a assimilação do } \\
\text { novo sistema de gestão; o desenvolvimento de } \\
\text { habilidades sócio-culturais para o relacionamento com } \\
\text { novas regras institucionais, novos acionistas e gestores. } \\
\text { Os membros participantes da reunião ocupam posição- } \\
\text { chave na disseminação de conhecimentos na } \\
\text { organização. Enquanto gerentes intermediários } \\
\text { exercem um papel importante como facilitadores das } \\
\text { aprendizagens de equipes em nível operacional. }\end{array}$ \\
\hline $\begin{array}{l}\text { Quais são as formas de interação privilegiadas } \\
\text { na cultura da organização? } \\
\text { Como pessoas e equipes tem aprendido ao } \\
\text { longo da história da organização? } \\
\text { Quais são as áreas ou equipes da organização } \\
\text { mais permeáveis a novas aprendizagens? }\end{array}$ & $\begin{array}{l}\text { A reunião é prática consagrada da cultura da } \\
\text { organização. Há alguns anos integra a rotina de } \\
\text { trabalho dessa unidade de serviços e não é apenas um } \\
\text { encontro formal. A reunião é também um espaço social } \\
\text { de interação e conversação. }\end{array}$ \\
\hline $\begin{array}{l}\text { Que situações específicas, inscritas na cultura } \\
\text { da organização e não necessariamente } \\
\text { associadas à educação formal, apresentam } \\
\text { potencial de aprendizagem? } \\
\text { Como o sentido coletivo é construído? }\end{array}$ & $\begin{array}{l}\text { Enquanto espaço de interação e de conversação, a } \\
\text { reunião favorece a transmissão de informação, } \\
\text { conhecimento, o compartilhamento e construção } \\
\text { coletiva de sentidos. }\end{array}$ \\
\hline
\end{tabular}

F IGURA II- QUADRO DA AVALIAÇÃo DE R EUNIÕES COMO OPORTUNIDADES DE APRENDIZAGEM Fonte: elaborada pela autora do artigo

Não se pode dizer que uma organização de aprendizagem poderia se estabelecer com esse tipo de avaliação de oportunidades de aprendizagem e intervenção. Contudo, vemos que essa reunião tem efeitos de aprendizagem e, como tal, poderia ser ativamente explorada nessa direção. $\mathrm{O}$ estabelecimento de estratégias de Recursos Humanos voltadas ao desenvolvimento de competências e aprendizagem organizacional devem, nesse caso, considerar essa reunião de trabalho como contexto privilegiado para a transmissão de informações e compartilhamento de sentidos.

\section{Feiras Setoriais}

A identificação de feiras setoriais como oportunidades de aprendizagem está associada ao estudo sobre o desenvolvimento da eficiência coletiva do cluster coureiro-calçadista existente no Vale do Rio dos Sinos (RS/Brasil). Assim como no exemplo das reuniões de trabalho, não se pretende generalizar essas situações para qualquer contexto organizacional, mas, diferente disso, chamar à atenção para oportunidades específicas que se apresentam caso a caso.

Duas vertentes de estudos sobre o Vale dos Sinos convergem na proposição de feiras setoriais como oportunidade de aprendizagem: (i) os estudos sobre competitividade do Vale dos Sinos; (ii) os estudos 
sobre a cooperação e a relação interfirmas no Vale dos Sinos.

Com relação à competitividade, análises do setor indicam que a tendência para a manutenção de vantagens competitivas do complexo coureiro-calçadista do Vale dos Sinos está associada ao desenvolvimento de canais de marketing próprios; à promoção da marca "made in Brasil"; à presença em Feiras Internacionais; e ao desenvolvimento de design próprio. Avaliações do setor sugerem que as empresas do complexo coureiro-calçadista do Vale dos Sinos já conseguiram superar o desafio da qualidade e produtividade mas não são capazes de competir internacionalmente no segmento de grandes lotes e baixo custo, considerando-se a presença asiática. Assim, uma saída competitiva para o Vale dos Sinos está no segmento de mercado no qual qualidade e design associam-se (Schmitz,2000).

Quanto à cooperação e à relação interfirmas, estudos realizados observam que a cooperação e a troca de informações, fatores que elevariam a eficiência coletiva da cadeia coureiro-calçadista do Vale dos Sinos, são ainda pouco explorados (FENSTERSEIFER E GOMES, 1995; RUAS, 1995; SCHMITZ, 1998).

Fensterseifer e Gomes (1995) observam que o complexo coureiro-calçadista do Vale dos Sinos carece de uma rede de troca de informações e cooperação tecnológica, ou seja, da comunicação contínua com usuários, fornecedores e concorrentes, além de monitoramento constante das inovações que ocorrem em outros setores. Ruas (1995) constata, entre outros aspectos, que a colaboração ou cooperação entre empresas que produzem o mesmo bem, estratégia presente nos clusters, é pouco explorada no Vale dos Sinos. O ocasional e o pessoal predominam no fluxo de informações. A cooperação interempresas está associada à amizade entre sócios e gerentes de empresas diferentes. $\mathrm{O}$ autor considera também que, no caso do complexo coureiro-calçadista do Vale dos Sinos, não se pode considerar que há troca de informações entre clientes e fornecedores, o que estabeleceria a diferença entre o cluster constituído espontaneamente e o cluster avançado pois é a interação e a troca de informações que viabilizam as iniciativas de cooperação. Na mesma direção dessas constatações, ouvimos do diretor-executivo de uma das associações patronais, voltada ao desenvolvimento de políticas compartilhadas de exportação, que as reuniões, cujo propósito formal seria o de identificar e desenvolver objetivos comuns, "são arenas", em que a disputa de poder e prestígio predominam sobre a troca de informações.

Schmitz (1998) indica que a cooperação vertical interfirmas tem avançado no Vale dos Sinos, contribuindo para a melhoria na qualidade do produto, velocidade de resposta e flexibilidade. No entanto, a cooperação voltada ao marketing, design e imagem da indústria e produtos do Vale dos Sinos não tem avançado. Para Schmitz, um pequeno grupo de grandes empresas, com programas de exportação bastante desenvolvidos junto aos principais compradores norte-americanos de calçados brasileiros, tende a desenvolver integrações verticais e, assim, afastar-se das iniciativas de cooperação que poderiam promover a eficiência coletiva do cluster.

Além dessas duas vertentes de estudos, em uma análise exploratória sobre a cadeia coureiro-calçadista do Vale dos Sinos baseada em entrevistas com lideranças locais e estudos de caso, identificourse que a participação de empresários em feiras nacionais e internacionais é um hábito observado há mais três décadas. Constitui-se em atividade importante não só para o fechamento de contratos, mas também para o contato desses empresários com as tendências da moda e novas tecnologias de produção. Em outra etapa dessa análise exploratória, concluiu-se avaliando-se as respostas a um questionário respondido por gerentes de 23 empresas da região que, com relação à participação em feiras \& eventos são valorizados aspectos como: troca de experiências; incentivo e capacitação para a exportação; promoção de imagem, marca e produtos; atualização tecnológica (maquinas, equipamentos, novos materiais); aproximação/parceria com fornecedores; aproximaçãol conquistal "contato ao vivo" 
delcom clientes, "visibilidade"; conhecimento (sintonia) de tendências de moda e características de mercados e segmentos específicos; e apresentação da empresa ao mercado nacional (SWIRSKI DE SOUZA, 2001).

Esses resultados de pesquisa sugerem que a interação através de feiras tem sido bem mais praticada e afim à cultura do Vale, do que outras iniciativas voltadas à promover a cooperação entre empresas.

Com esses elementos e diante das questões: (i) que aprendizagens são cruciais para as empresas da cadeia coureiro-calçadista do Vale dos Sinos?; (ii) como essas aprendizagens podem ser desenvolvidas e otimizadas considerando-se as realidades sociais e culturais específicas do contexto organizacional?; e observando-se, ainda, as características dos processos de aprendizagem organizacional destacados, as feiras setoriais podem ser avaliadas como oportunidades de aprendizagem conforme exposto na figura abaixo.

\begin{tabular}{|c|c|}
\hline \begin{tabular}{|llrr} 
Questões orientadoras & para & o \\
desenvolvimento de & processos & de \\
aprendizagem & & &
\end{tabular} & $\begin{array}{l}\text { Avaliação das feiras setoriais como oportunidades de } \\
\text { aprendizagem para empresas da cadeia coureiro- } \\
\text { calçadista do Vale do Rio dos Sinos }\end{array}$ \\
\hline $\begin{array}{l}\text { Que aprendizagens e que conhecimentos são } \\
\text { cruciais para assegurar competitividade à } \\
\text { organização? }\end{array}$ & $\begin{array}{l}\text { Favorecem a aprendizagens estrategicamente } \\
\text { relevantes como a assimilação de novas tendências da } \\
\text { moda e novas tecnologias. Facilita à construção do } \\
\text { conhecimento com relação aos desejos e demandas dos } \\
\text { clientes internacionais, o que é chave para a } \\
\text { internacio nalização e construção de marca própria. }\end{array}$ \\
\hline $\begin{array}{l}\text { Quem são os atores-chave na busca de } \\
\text { informação? } \\
\text { Quais e como são as estratégias e políticas da } \\
\text { organização para o desenvolvimento de } \\
\text { competências associadas à aprendizagem } \\
\text { entre os atores-chave? } \\
\text { Que condições estruturais e de interação os } \\
\text { atores-chave encontram para disseminar } \\
\text { informações? }\end{array}$ & $\begin{array}{l}\text { Os membros participantes de feiras ocupam posição- } \\
\text { chave com relação às estratégias das empresas do } \\
\text { setor. O empresário e a alta direção das empresas } \\
\text { participam de Feiras, como expositores e visitantes. } \\
\text { Grande parte das empresas da cadeia coureiro- } \\
\text { calçadista tem estrutura simples. Assim, a informação } \\
\text { flui de modo informal do participante da Feira para os } \\
\text { responsáveis pela elaboração dos modelos e, logo, para } \\
\text { a produção. }\end{array}$ \\
\hline $\begin{array}{l}\text { Quais são as formas de interação privilegiadas } \\
\text { na cultura da organização? } \\
\text { Como pessoas e equipes tem aprendido ao } \\
\text { longo da história da organização? } \\
\text { Quais são as áreas ou equipes da organização } \\
\text { mais permeáveis a novas aprendizagens? }\end{array}$ & $\begin{array}{l}\text { A participação em feiras é hábito já consagrado entre } \\
\text { os empresários do Vale dos Sinos. Trata-se, assim, de } \\
\text { prática inscrita na cultura organizacional das empresas } \\
\text { da cadeia coureiro-calçadista. }\end{array}$ \\
\hline $\begin{array}{l}\text { Que situações específicas, inscritas na cultura } \\
\text { da organização e não necessariamente } \\
\text { associadas à educação formal, apresentam } \\
\text { potencial de aprendizagem? } \\
\text { Como o sentido coletivo é construído? }\end{array}$ & $\begin{array}{l}\text { As feiras apresentam-se como situações nas quais as } \\
\text { interações e inter-relações são intensificadas, } \\
\text { oferecendo, em geral, uma quantidade elevada de } \\
\text { informações. O ambiente informal, festivo e } \\
\text { descontraído das Feiras é favorável ao estabelecimento } \\
\text { de aprendizagens sociais. }\end{array}$ \\
\hline
\end{tabular}

FIGURA III- QUADRO DA AVALIAÇÃo DE
APRENDIZAGEM
Fonte: elaborada pela autora do artigo


Do mesmo modo como afirmávamos acima, com relação ao caso das reuniões de trabalho, não se pretende, ao se identificar feiras setoriais como oportunidades de aprendizagem, afirmar que através das mesmas serão estabelecidas organizações de aprendizagem no Vale dos Sinos. Mas, diferente disso, entende-se que a aprendizagem organizacional pode ser desenvolvida e otimizada, sendo as feiras um caminho.

Otimizar essa oportunidade significa tratar a participação em feiras não apenas como uma ação fortuita das empresas mas uma ação a ser administrada ativamente. Isto significa desenvolver ações como, por exemplo, registrar, arquivar e disseminar as informações propiciadas pela participação em uma Feira; incorporar as aprendizagens e conhecimentos favorecidos em uma Feira aos em processos, produtos, serviços; favorecer a que os representantes da empresa que participam em uma Feira encontrem vias para a transmissão de suas aprendizagens; etc...

\section{CONSIDERAÇÕES FINAIS}

A preocupação que acompanha esse artigo é a de chamar à atenção para possibilidades de desenvolvimento e otimização de processos de aprendizagem organizacional, levando-se em conta as realidades sociais e culturais dos contextos organizacionais.

Buscamos destacar que existem caminhos para a prática da aprendizagem organizacional que não se restringem às idéias de A quinta disciplina de Peter Senge e sua proposição das organizações de aprendizagem.

Embora a proposição das organizações de aprendizagem seja instigante e, até, desafiadora, ela tem sido considerada como uma visão retórica e alicerçada em fantasias. Para o praticante, a comparação entre a proposição das organizações de aprendizagem e o cotidiano das empresas conduz a constatações via de regra desanimadora com relação às condições de aprendizagem das últimas.

Valorizando aspectos dos processos da aprendizagem organizacional como: serem chave para a competitividade e sobrevivência de organizações; tratarem-se de fenômeno ao mesmo tempo individual e coletivo; estarem intrinsecamente relacionados à cultura das organizações; e constituírem-se em um fenômeno que implica a paradoxal associação entre ordem e desordem, entendemos que ações voltadas à aprendizagem organizacional podem ser desenvolvidas e otimizadas.

Com a noção de oportunidades de aprendizagem organizacional aqui proposta, pretendemos designar momentos e situações que, já inscritos na cultura e nas formas privilegiadas de ação da organização, são propícios à aprendizagem.

Vimos que reuniões de trabalho e feiras setoriais podem ser qualificadas como oportunidades de aprendizagem, considerados os seus contextos organizacionais específicos.

Sem pretender ou esperar que se possa converter organizações em organizações de aprendizagem, observamos que aprendizagens são intrínsecas à dinâmica das organizações. O desafio do praticante é o compreender a natureza dos contextos organizacionais específicos e, então, identificar oportunidades de aprendizagem singulares aos mesmos.

Cabe, por fim, ressaltar que a presente abordagem ao tema da aprendizagem organizacio nal representa uma etapa em um programa de pesquisa. Aqui estabelecemos um esquema conceitual básico que é explorado em dois casos. Novos estudos são necessários. Identificar indicadores da aprendizagem organizacional associados aos aspectos aqui destacados é um trabalho ainda a ser realizado. Indicadores 
de aprendizagem poderão propiciar análises não só qualitativas, como também quantitativas da aprendizagem organizacional que são relevantes sempre que se tem o propósito de intervenção e mudança.

\section{Artigo recebido em 30.01.2003. Aprovado em 10.11.2003}

\section{REFERÊNCIAS BIBLIOGRÁFICAS}

ANTONACOPOULOU, Elena. Desenvolvendo gerentes aprendizes dentro de organizações de aprendizagem: o caso de três dês bancos varejistas. In Smith, Mark Easterby et alli. Aprendizagem organizacional e organização de aprendizagem. São Paulo: Atlas, 2001, pp. 263-288.

ARGYRIS, C. On organizational learning. Cambridge, MA: Blackwell, 1992a.

. Enfrentando defesas empresariais. Rio de Janeiro: Campus, $1992 \mathrm{~b}$.

ARGYRIS, C. e SCHÖN, D. Organizational learning: a theory of action perspective. Massachusetts: Addison-Wesley, 1978.

COOK, S. e YANOW, D. COOK, S. e YANOW, D. Culture and organizational learning. In Michael Cohen e Lee Sproull (org.). Organizational learning. Londres: SAGE, 1996, pp. 430-460.

DODGSON, M. Organizational Learning: a review of some literatures. Organization Studies, vol.14, n³, pp.375-394, 1993.

DIXON, Nancy. Aprendendo através das fronteiras organizacionais: um estudo de caso em museus canadenses. In Smith, Mark Easterby et alli. Aprendizagem organizacional e organização de aprendizagem. São Paulo: Atlas, 2001, pp. 148-164.

. The hallways of learning. Organizational Dynamics. Spring, pp. 23-34, 1997.

FENSTERSEIFER, J e GOMES, J. Análise da cadeia produtiva do calçado do couro. In $O$ complexo calçadista em perspectiva: tecnologia e competitividade., pp 23-53. Porto Alegre: Ortiz, 1995.

HAWKINS, Peter. Organizational learning: taking stock and facing the challenge. Londres, Management Learning, vol. 25, nº 1, pp. 71-82, 1994.

HEDBERG, B. How organizations learn and unlearn. In Nystrom, P.C. e Starbuck, W.H. (eds), Handbook of organizational design (pp. 3-27). Londres: Oxford University Press, 1981.

JACKSON, B.. G. A fantasy theme analysis of Peter Senge's learning organization. Arlington, USA, The Journal of Applied Behavioral Science, vol. 36, nº 2, pp. 193-209, 2000.

KIM, D. The link between individual and organizational learning. Sloan Management Review, (fall), pp. 37-50, 1993.

LIPSHITZ, R.; POPER, M. e Oz, S. Building learning organizations: the design and implementation of organization learning mechanisms. Journal of Applied Behavioral Science, vol.32, n³, pp. 292-305, 1996. 


\section{ORGANIZAÇÕES - ORGANIZAÇÕES DE APRENDIZAGEM OU APRENDIZAGEM ORGANIZACIONAL \\ Yeda Swirski de Souza}

NONAKA, I. A dynamic theory of organizational knowledge. Organization Science, vol.5, n⿳⺈, pp.1437, 1994.

RUAS, R. O conceito de cluster e as relações interfirmas no complexo calçadista do Rio Grande do Sul. In: O complexo calçadista em perspectiva: tecnologia e competitividade., pp 55-95. Porto Alegre: Ortiz, 1995.

SCHEIN, E. Organizational Culture. American Psychologist, vol.45, n², pp. 109-119, 1990.

Culture: the missing concept in organization studies. Administrative Science Quarterly, vol. 41, pp.229-240, 1996.

SCHMITZ H. Responding to global competitive pressure: local co-operation and upgrading in the Sinos Valley, Brazil. Institute of Development Studies, working paper, 1998.

Seminário Nacional da Indústria de Calçados. Novo Hamburgo: ABICALÇADOS, ASSINTECAL e Centro das Indústrias de Curtumes do Brasil, palestra, notas pessoais, 18 a 20/10/2000.

SENGE, P. A quinta disciplina. São Paulo: Best Seller, 1992.

SIMON, H. Sciences of the artificial. Cambridge, MA: MIT Press, 1969.

WEICK, K. e WESTLEY, F. Organizational learning: affirm and oxymoron, In Clegg, S., Hardy, C. \& Nord, W. R. (org.). Handbook of Organizational Studies (pp.440-458). Londres: Sage, 1996.

SWIRSKI DE SOUZA, Y. Aprendizagem organizacional: feiras e eventos como oportunidade para a cadeia coureiro-calçadista do Vale do Rio dos Sinos. XXV ENANPAD, anais, 2001.

Aprendizagem organizacional, conversação e produção de sentido. PUCRS: Faculdade de

Psicologia, Tese de Doutorado, 1999.

\footnotetext{
i A quinta disciplina foi originalmente publicada em 1990, com primeira edição no Brasil em 1992.

ii A referência Arquimedes.

iii Fonte: site http://www.livcultura.com.br acesso em 08/02/2002.

iv Tradução sob nossa responsabilidade.
}

\section{Yeda Swirski de Souza}

Doutora em Psicologia, professora e pesquisadora do Pós-Graduação em Administração da UNISINOS E-mail: yedasou@ portoweb.com.br

Endereço: Av Iguaçu, 188 - ap. 401, Petrópolis, Porto Alegre - RS, 90470- 430

Interesses de Pesquisa: mudança e aprendizagem organizacional, cooperação e confiança, subjetividade e gestão. 